\title{
Thyristor Based Short Circuit Current Injection in Isolated Grids
}

\author{
Bjarte Hoff, Pawan Sharma and Trond Østrem \\ Department of Electrical Engineering \\ UiT The Arctic University of Norway \\ Narvik, Norway \\ bjarte.hoff@uit.no
}

\begin{abstract}
This paper proposes a thyristor based short circuit current injector for providing short circuit current in isolated and weak grids, where sufficient fault current to trigger circuit breakers may not be available. This will allow the use of conventional miniature circuit breakers, which requires high fault current for instantaneous tripping. The method has been validated through experiments.
\end{abstract}

Keywords-Power system protection; microgrids; thyristors; circuit breakers; short circuit currents; power electronics

\section{INTRODUCTION}

Protection in low voltage electrical installations are based on circuit breakers or fuses, which detect and trigger on overload and short circuits. Circuit breakers, such as the miniature circuit breakers (MCB), are normally made up of a bimetallic strip and a solenoid, protecting the installation from overload and short circuit, respectively. These devices depends on a fault current, exceeding the nominal current, flowing through the device to operate. The instantaneous tripping current for a circuit breaker is defined as the "minimum value of current causing the circuit-breaker to operate automatically without intentional time-delay" [1].

In weak or isolated grids like microgrids, the fault current might be too low to trigger the MCB within the permitted time limit. This is one of the challenges related to protection of microgrids mentioned in [2]. If a microgrid experiences a blackout from a short circuit, it can take some time to locate the fault if no circuit breakers trips and isolates the fault. Restoration of power might not be possible until a skilled technician has repaired the installation or disconnected the faulty circuit.

Research on microgrid protection has focused on new advanced protection concepts, often utilizing communication $[3,4]$ and centralized control $[5,6]$. This results in a more complicated and expensive solution compared to the relatively cheap mass-produced MCBs. Different fault current sources are mentioned in [7], but focus more on injecting a sinusoidal fault current for fault ride through capabilities.

The main contribution in this paper, is a new topology for a thyristor based short circuit current injector (SCCI) to supply fault current to the grid. Conventional mass-produced and cheap protection devices such as fuses and MCB can thereby operate as intended. While this paper only presents a singlephase grid, the proposed method can be extended to threephase using wye or delta connection.

\section{Miniature CiRCUIT Breaker Characteristics}

The standard for circuit breakers are available in [1] for households and [8] for industry. They generally follow the time-current characteristic in Fig. 1, where the following currents is defined as a multiple of the rated current $\mathrm{I}_{\mathrm{N}}$ :

- $\mathrm{I}_{1}$ is the lowest current in which the MCB may trip on overload within one hour.

- $\mathrm{I}_{2}$ is the lowest current in which the $\mathrm{MCB}$ is required to trip within one hour.

- $\mathrm{I}_{4}$ is the lowest current in which the MCB may achieve instantaneous tripping

- $\mathrm{I}_{5}$ is the lowest current that guarantees instantaneous tripping.

Instantaneous tripping is required to disconnect and isolate short circuit faults quickly enough to minimize the risk of fire and electric shock. Due to the limited ability of power electric converters to handle over currents, isolated grids such as microgrids, also depends on instantaneous tripping to avoid blackout of the entire installation.

A MCB may instantaneous trip with a fault current above a certain limit, $\mathrm{I}_{4}$. Due to the tolerance described in [1], a fault current of $\mathrm{I}_{5}$ or above is required to guarantee this result. Instantaneous tripping range for the most common types found in households are shown in Table I.

TABLE I. RANGES OF INSTANTANEOUS TRIPPING OG MCBS

\begin{tabular}{|l|c|c|}
\hline \multirow{2}{*}{ Type } & \multicolumn{2}{|c|}{ Range } \\
\cline { 2 - 3 } & $\boldsymbol{I 4}$ & $\boldsymbol{I 5}$ \\
\hline $\mathrm{B}$ & $3 \cdot I_{N}$ & $5 \cdot I_{N}$ \\
\hline $\mathrm{C}$ & $5 \cdot I_{N}$ & $10 \cdot I_{N}$ \\
\hline $\mathrm{D}$ & $10 \cdot I_{N}$ & $20 \cdot I_{N}$ \\
\hline
\end{tabular}

This paper is a part of the Arctic Energy project founded by the Interreg Nord EU-program, and Nordland and Troms County Council, Norway. 


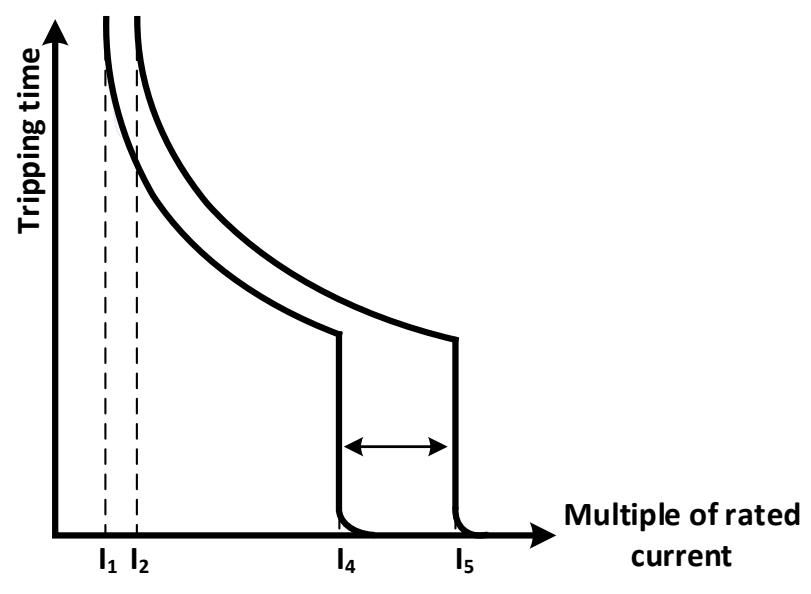

Fig. 1. Characteristic of MCBs

In addition, the current needs to be sustained long enough for the electromagnetic solenoid in the MCB to activate. In [1], the tripping time is required to be less than $0.1 \mathrm{~s}$. This time also includes the time it takes for the MCB to mechanical open its switches and extinguish the arc. The minimum time required to activate instantaneous tripping is not specified in the standard and therefore unknown. It may also vary between manufactures. Since detailed MCB modelling or comprehensive laboratory testing is out of the scope for this paper, a maximum time of $0.1 \mathrm{~s}$ is considered, in addition to an estimated activation time of $3 \mathrm{~ms}$ for comparison.

\section{Short Circuit CURRENT INJECTOR}

The thyristor based short circuit injector (SCCI) in Fig. 2 is proposed to in inject fault current into the local grid to ensure instantaneous tripping in case of a short circuit. It consist of an energy storage (capacitor $\mathrm{C}_{1}$ ), a power electronic switch (thyristor $\mathrm{T}_{1}$ ), charging diode $\mathrm{D}_{1}$, and current limiting resistors $R_{1}$ and $R_{2}$. Based on the energy requirements, the capacitor is chosen to have sufficient storage capacity to trip the circuit breaker.

When a short circuit occurs, the grid voltage drops to near zero. Activation of the device cause a current to flow through $\mathrm{T} 1$, discharging the capacitor. This current flows through the short circuit until the circuit breaker trips and isolates the fault from the grid.

Diode D1 allows the capacitor to recharge through the limiting resistor R1. By limiting the recharge current through $\mathrm{D} 1$, an inrush current is avoided as the grid recovers to nominal voltage. The diode rectifier based recharging also ensures the capacitor voltage never to exceed the grid amplitude. The resistor R2 can limit the discharge current to protect the capacitor from overcurrent, if the short circuit occurs with negligible impedance close to the device.

The SCCI is intended applied in isolated or weak grids with low short circuit currents. It is therefore sufficient to inject fault current in only one direction, since the injected current is significantly higher than the grid supplied fault current. In the positive half period, the grid will contribute to the short circuit current, while in the negative half period, the grid will absorb

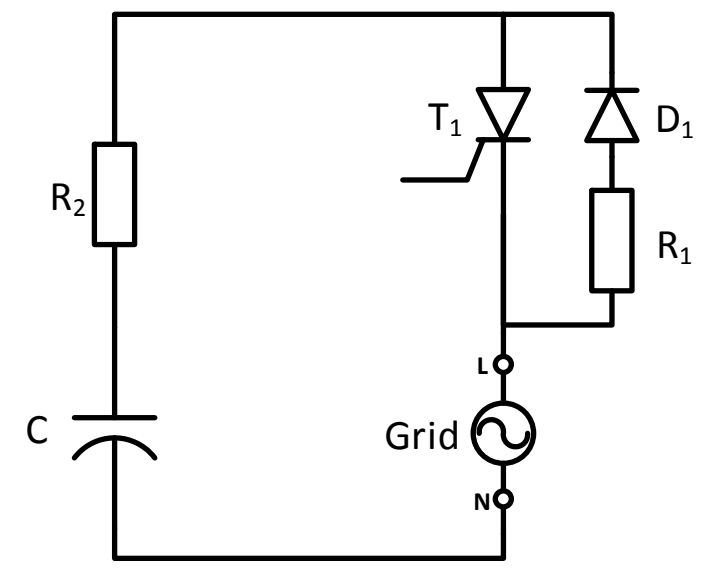

Fig. 2. Thyristor based short circuit current injector

some of the injected current. If only limited fault current is available, this effect would be tolerable. However, it is recommended to inject short circuit current only in the positive half period.

If the energy source in the SCCI is considered to be a capacitor, a short circuit can be modelled as a RC-circuit:

$$
i(t)=\frac{\hat{V}_{g}}{R_{S C}} e^{-\frac{t}{R_{S C} C}},
$$

where $\hat{V}_{g}$ is the grid amplitude equal to the initial capacitor voltage, and $\mathrm{R}_{\mathrm{SC}}$ is the fault resistance during short circuit. To ensure instantaneous tripping, the fault current should be $i(t) \geq I_{5}$ during the circuit breaker opening time, where $I_{5}$ is defined as the minimum required current to guarantee instantaneous tripping.

The minimum capacitor value that guaranties to trigger the circuit breaker, can be derived from (1):

$$
C=\frac{-t_{0}}{R_{S C} \ln \left|\frac{I_{5} R_{S C}}{\hat{V}_{g}}\right|},
$$

where $t_{0}$ is the MCB tripping time. If the tripping time is set to $100 \mathrm{~ms}$, which is a common specified maximum value for MCBs [9], the minimum capacitor value versus fault resistance is shown in Fig. 3.

Since the circuit breaker in most cases will demonstrate a shorter tripping time and with lower current than $\mathrm{I}_{5}$, one could expect the required capacitance to ensure instantaneous tripping being significantly lower than the limit in Fig. 3.

In Fig. 4, tripping time of $3 \mathrm{~ms}$ shows a significant decrease in the capacitor requirements compared to $100 \mathrm{~ms}$. A comprehensive set of experiments is required to determine the exact minimum fault current duration for different types and manufactures of MCBs. 


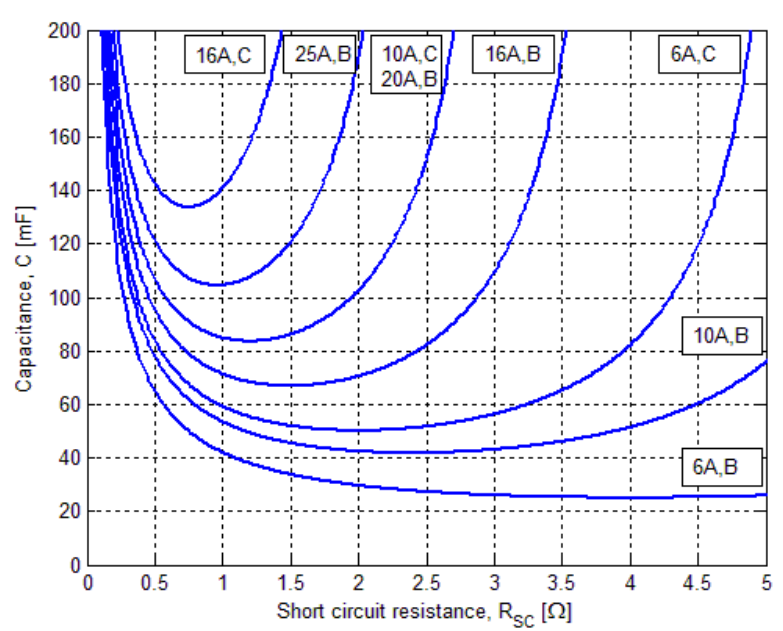

Fig. 3. Minimum capacitor value versus SC resistance for $t_{0}=100 \mathrm{~ms}$

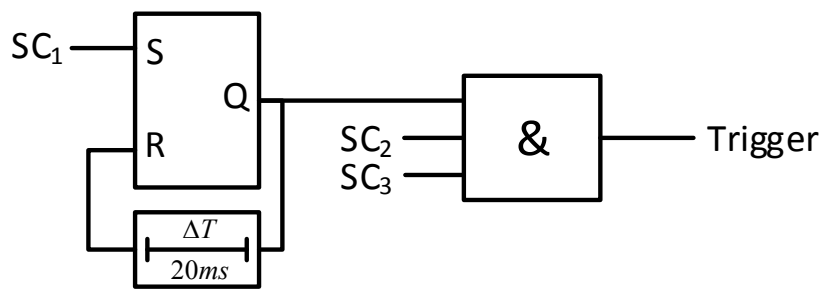

Fig. 5. Control algorithm trigger logic

\section{CONTROl Algorithm}

The control algorithm for the SCCI consist of a voltage sensor and detection unit that triggers the thyristor if a short circuit is detected. A short circuit would cause a sudden drop in grid voltage. Provided negligible fault impedance, grid voltage is close to zero as long as the fault is present. This is utilized by the algorithm to detect a short circuit based on instantaneous voltage error. The algorithm trigger logic in Fig. 5 is based on three criteria, SC1, SC2 and SC3.

The first criterion detects a short circuit in positive and negative half period using:

$$
\begin{gathered}
S C_{1}=\left\{\begin{array}{cc}
0 & |e(t)|<\alpha \cdot \hat{V}_{g} \\
1 & e(t) \geq \alpha \cdot \hat{V}_{g}, \\
1 & e(t) \leq-\alpha \cdot \hat{V}_{g}
\end{array}\right. \\
e(t)=v(t)-\hat{V}_{g} \sin (\theta),
\end{gathered}
$$

where $\mathrm{v}(\mathrm{t})$ is the measured grid voltage and the voltage angle $\theta$ can be found using a phase-locked loop (PLL). The error limit for triggering the SCCI is determined by the grid amplitude multiplied by a factor $\alpha \in[0,1]$. The value of this factor depends on the voltage quality in the grid. The higher the factor, the less sensitive the controller will be.

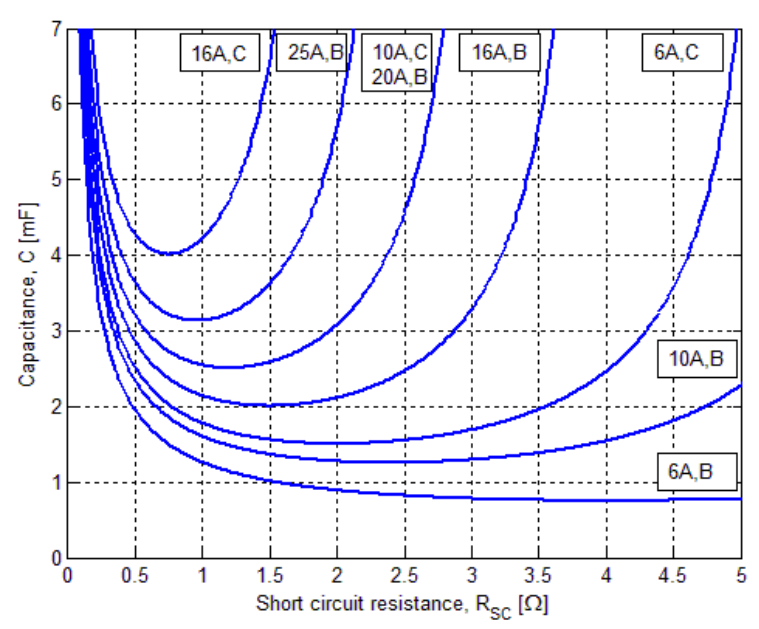

Fig. 4. Minimum capacitor value versus SC resistance for $t_{0}=3 \mathrm{~ms}$

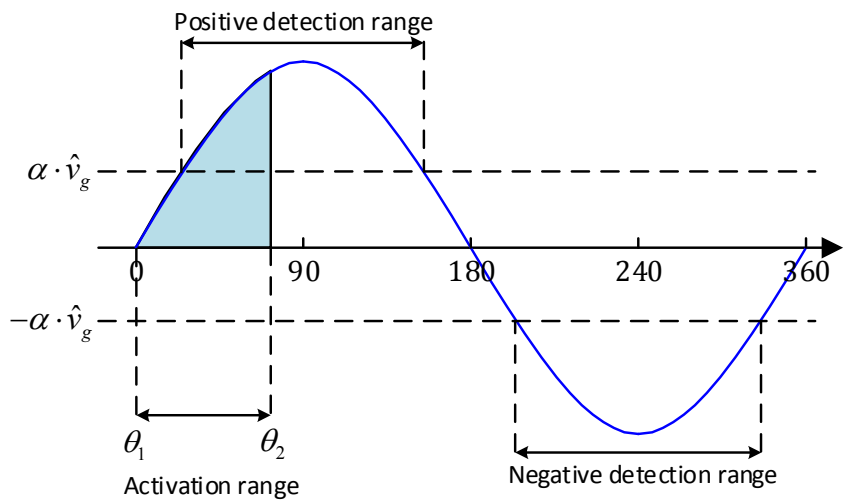

Fig. 6. Control algorithm detection and activation range

Equation (3) defines the ranges where a short circuit can be detected, shown as positive and negative detection range in Fig. 6. If necessary, it is assumed that a low pass filter is used to remove high frequency measurement noise prior to the control algorithm.

A second criterion can be imposed, which limits where in the period SCCI is allowed to be activated. This activation range is defined as:

$$
S C_{2}=\left\{\begin{array}{cc}
0 & \theta(t)<\theta_{1} \\
0 & \theta(t)>\theta_{2} \\
1 & \text { otherwise }
\end{array},\right.
$$

This can ensure that the injected current is in the same direction as the short circuit current already supplied from the grid. The required capacitance for supplying enough fault current is thereby lowered.

In Fig. 6, the activation range is shown in the first part of the positive half period up to $80^{\circ}$. The objective is to activate the SCCI, trigger the MCB and isolate the fault within the positive half period of the grid voltage. 
A third criterion only allows the SCCI to activate when the capacitor voltage $u_{C}$ is sufficiently high. A factor $\beta$ defines this limit related to the grid voltage amplitude:

$$
S C_{3}=\left\{\begin{array}{ll}
0 & u_{C}(t)<\beta \hat{v}_{g} \\
1 & u_{C}(t) \geq \beta \hat{v}_{g}
\end{array} .\right.
$$

Since charging of the capacitor is limited by the resistor $R_{1}$, the criteria in (6) also prevents repeatedly triggering the device.

The combined algorithm is formed using the logic in Fig. 5. A monostable flip-flop is used as a temporary memory for the SC1 signal. This is necessary to remember the detected short circuit until the activation range is reached.

\section{GRID IMPACT}

When connecting the SCCI to the local grid as shown in Fig. 7, the injected current and imposed voltage will be visible to all connected components, not only the faulty circuit. It is important that the SCCI do not cause damage to other electrical devices.

In addition, IT equipment should be able to operate without interruption, if the grid source is able to recover the grid to nominal voltage after the fault has been isolated by the MCB.

In the following subsections, three cases of grid impacts are considered.

\section{A. Continous operation of IT-equipment}

According IEC 61000-4-11 [10] and IEC 61000-4-34 [11], class II IT equipment are required to handle 1 cycle $(20 \mathrm{~ms}$ in a $50 \mathrm{~Hz}$ grid) without power. If the grid voltage then increases to $70 \%$ of nominal voltage for up to 25 cycles before returning to normal operating conditions, continuous operation without interruptions is expected. The experiments in section VI will use these requirements as minimum acceptable performance.

\section{B. Sudden change of grid voltage}

After activation, the SCCI connects a fully charged capacitor directly to the local grid. The voltage can go from near zero to peak value in an instant, followed by a gradual decrease as the capacitor discharges. Since the capacitor will not be charged above the grid amplitude, this situation is similar to turning on a switch. A manual switch or plug is not synchronized with the grid, and may well be connected just as the voltage is at its highest. The activation of SCCI should therefore not be able to damage other connected devices just by a sudden change in voltage.

\section{Transient overvoltages}

When a high current is injected into the grid, the current takes the path of least resistance. In the case of a short circuit, the faulty circuit will carry the majority of the current. When the MCB trips and disconnects the fault, inductive elements in the grid can cause high voltage spikes that can damage electrical devices.

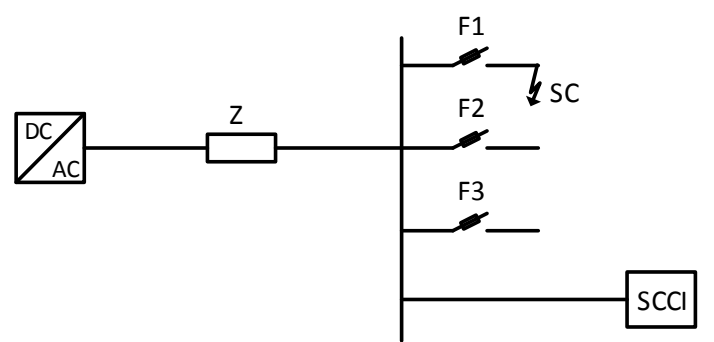

$$
\text { Source } \mid \text { Grid impedance } \mid \text { Switch board } \mid \begin{gathered}
\text { Short circuit } \\
\text { cu rrent injector }
\end{gathered}
$$

Fig. 7. Isolated single-phase grid

While this can occur when activating the SCCI, the same phenomena will occur if the installation is connected to a strong grid. In fact, the short circuit current will normally be lower using SCCI, compared to a strong grid. Include that the SCCI would be relatively close to the fault location, the total inductance in the current path are expected to be lower. A conventional surge protection device (SPD) already installed in most modern buildings should be sufficient to avoid damage. An additional SPD is always recommended for protecting individual sensitive equipment.

A second source of transient overvoltage is the inverter, which operates at maximal current during a short circuit. When the fault is disconnected by the MCB, high voltage transients can be introduced if the inverter control algorithm is not able to adjust quickly. Again, this problem is present with or without the SCCI. Inverter fault ride-trough capabilities and dynamic response are considered out of the scope for this paper.

\section{EXPERIMENTAL SETUP AND RESULTS}

An experimental setup is built as shown in Fig. 8, while component values are shown in Table II. A resistor, $R_{g}$ in series with a stiff grid creates a weak grid that emulates a current limited source. The resistor is selected large enough to reduce the short circuit current for which the MCB will not trigger instantaneously, in case of a short circuit. In this setup, the source will supply a short circuit current of maximum:

$$
\hat{I}_{S C, \text { grid }}=\frac{\hat{V}_{g}}{R_{g}}=\frac{241 \mathrm{~V} \cdot \sqrt{2}}{10 \Omega}=34 \mathrm{~A} .
$$

This setup is representative for a small microgrid in island mode, where renewable energy sources and power electronic converters only can supply a limited amount of fault current. It also emulates a weak grid, but such weak grids are considered unrealistic in most grid-connected applications.

A short circuit is created by using a manual switch (-S1), while the SCCI controller is implemented using a dSpace 1104 rapid prototyping system. The controller triggers the SCCI thyristor $T_{1}$ according to the control algorithm described in section IV. A PLL based on the suggested design in [12] is used to estimate the grid voltage angle, $\theta(t)$. 


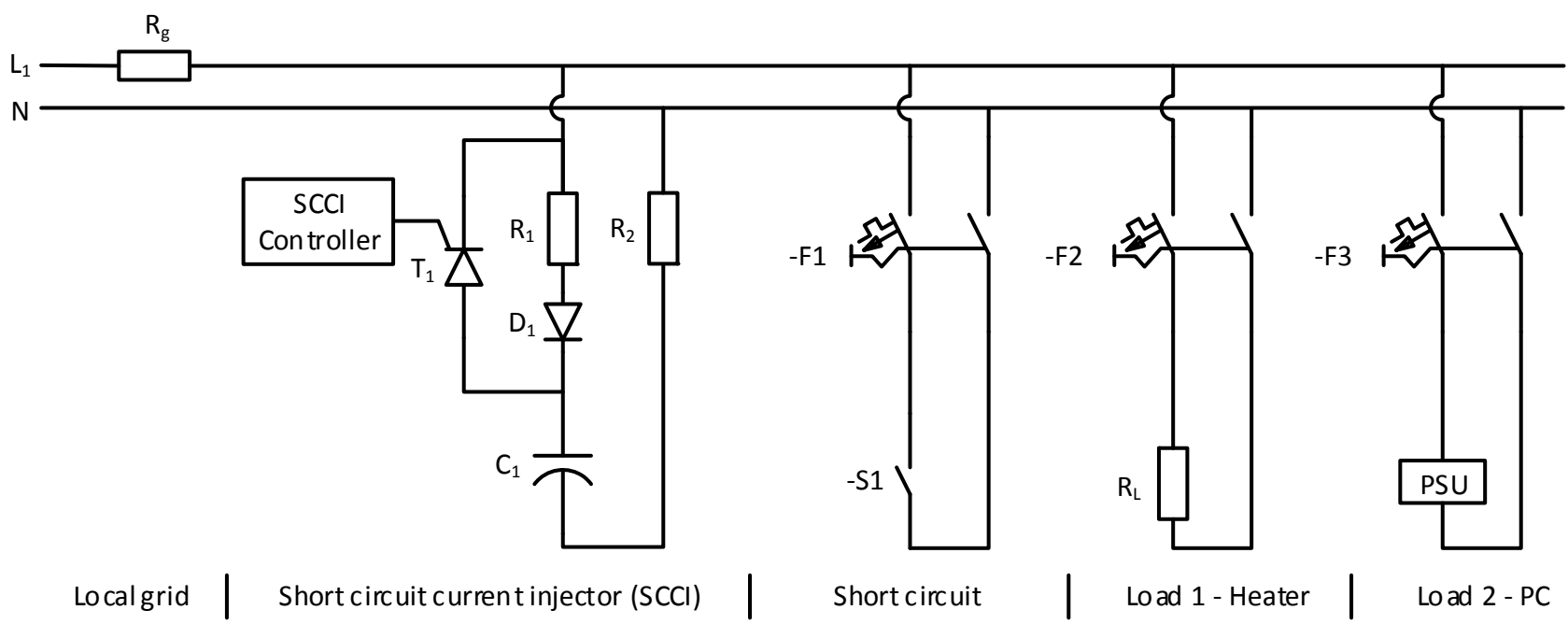

Fig. 8. Experimental setup with SCCI and load in a weak grid

TABLE II. EXPERIMENT PARAMETERS

\begin{tabular}{|c|l|c|}
\hline Symbol & \multicolumn{1}{|c|}{ Description } & Value \\
\hline$R_{g}$ & Grid impedance & $10 \Omega$ \\
\hline$R_{I}$ & Charge current limiting resistor & $613 \Omega$ \\
\hline$R_{2}$ & SCCI current limiting resistor & $1.6 \Omega$ \\
\hline$R_{L}$ & Resistive load, 500W & $106 \Omega$ \\
\hline$C$ & Capacitor, 450VDC & $2200 \mu \mathrm{F}$ \\
\hline$-F 1$ & MCB, ABB S 262 & $10 \mathrm{~A}, \mathrm{~B}$ \\
\hline$T_{I}$ & Thyristor GE C355M & $600 \mathrm{~A}$ \\
\hline$D_{I}$ & Diode GE A396N & $250 \mathrm{~A}$ \\
\hline$\alpha$ & Fault detection factor & 0.40 \\
\hline$\beta$ & Capacitor charge factor & 0.95 \\
\hline$\theta_{1}$ & Lower limit of trigger range & $0^{\circ}$ \\
\hline$\theta_{2}$ & Upper limit of trigger range & $80^{\circ}$ \\
\hline$T_{s}$ & Controller time step & $100 \mu \mathrm{s}$ \\
\hline
\end{tabular}

In addition to the circuit where the short circuit is created, two additional circuits are connected to the local grid. A 500W resistive heater is connected to circuit breaker $-\mathrm{F} 2$, while a desktop computer with LCL display is connected to $-\mathrm{F} 3$. The computer is an Intel $\mathrm{i} 7$ based PC, which is running scandisk of drive $\mathrm{C}$ at the time of the experiment. Continuous operation of the $\mathrm{PC}$ during a short circuit is considered as a successful use of the SCCI, in addition to the requirements in section V. A.

Grid and capacitor voltages are measured using LEM elements, while the injected short circuit current is measured using Fluke i6000s Flex with a 600A measurement range.

For the test, $-\mathrm{F} 1$ is a $10 \mathrm{~A} \mathrm{MCB}$ with B-characteristic, which requires a fault current between 30-50A for instantaneous tripping. The tripping time is specified to less than $0.1 \mathrm{~s}$ in the datasheet. Precise duration required of the fault current is therefore unknown and must be determined by experiments.
The experimental result is captured by an Agilent DSO-X 2004A oscilloscope and presented as MATLAB plots. No filtering is applied to either measurements or results.

Before the short circuit is applied, the local grid voltage is measured to $217 \mathrm{~V} \mathrm{RMS}$ and the capacitor is charged to $264 \mathrm{~V}$ DC. Two experiments are performed, with and without the proposed SCCI.

\section{A. Experiment with SCCI activated}

The result from using SCCI is shown in Fig. 9. After the short circuit is created by closing switch $-\mathrm{S} 1$ at $t=0$, the grid voltage drops to zero. While the control algorithm detected the short circuit, it does not activate the SCCI before entering the defined activation range. The following events takes place:

- $\mathrm{T}=0 \mathrm{~s}$ : Short circuit is created

- $\mathrm{T}=1.6 \mathrm{~ms}$ : SCCI is activated

- $\mathrm{T}=3.5 \mathrm{~ms}: \mathrm{MCB}-\mathrm{F} 1$ trips and start opening its mechanical switches to break the fault current

- $\mathrm{T}=10 \mathrm{~ms}$ : The short circuit is isolated and grid voltage returns to normal operation

The grid voltage experienced half a cycle without power, which is within the immunity requirements in section V.A. As expected, the PC continued to operate without interruption during the experiment.

In this experiment, the $\mathrm{MCB}-\mathrm{F} 1$ trips and starts opening its mechanical switches after being exposed to the fault current for $2 \mathrm{~ms}$. It then takes another $6.5 \mathrm{~ms}$ for the MCB to completely open and break the short circuit current, due to mechanical delay and arcing. Based on these observations, the capacitance requirement becomes:

$$
C \geq \frac{-t_{0}}{R_{2} \ln \left|\frac{I_{5} R_{S C}}{V_{C 1}}\right|}=\frac{-0.002 \mathrm{~s}}{2.6 \Omega \ln \left|\frac{50 \mathrm{~A} \cdot 1.6 \Omega}{264 \mathrm{~V}}\right|}=0.64 \mathrm{mF},
$$

which is well within the $2200 \mu \mathrm{F}(2.2 \mathrm{mF})$ used in the experimental setup. 

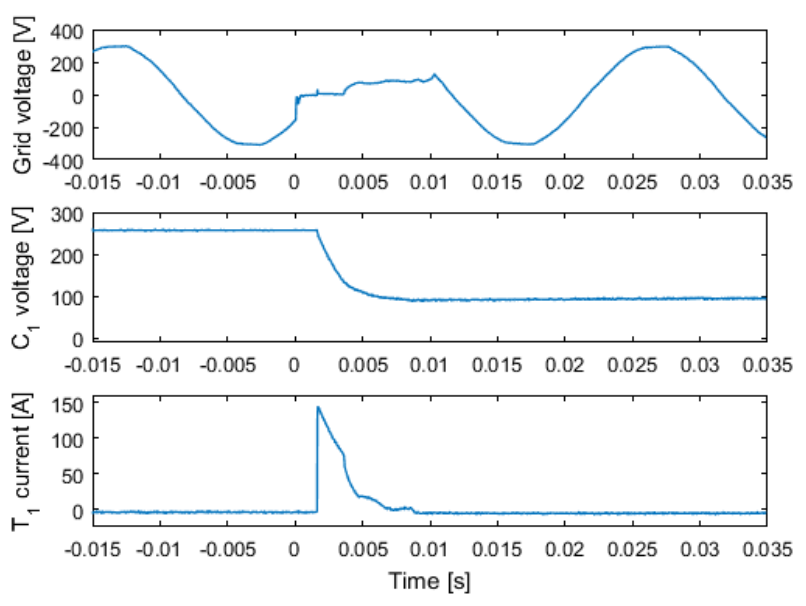

Fig. 9. Short circuit with SCCI activated

\section{B. Experiment with SCCI deactivated}

For comparison, the experiment is repeated with SCCI deactivated. The result in Fig. 10 shows the grid voltage to drop to zero when a short circuit is introduced, as expected. In contrast to the previous experiment, the SCCI is not activated. The MCB does not instantaneous trip and the grid voltage remains at zero.

Eventually, the MCB -F1 would trip on overload, but this can take from 3 seconds up to 1.5 minutes. With an interruption well above 1 cycle, the connected PC stopped working.

If this was a microgrid, it is likely that the inverters supplying the grid would shut down, resulting in a blackout. A technician would manually have to locate and isolate the faulty circuit (in this case -F1) before the grid can be recovered.

\section{CONCLUSION}

A short circuit current injector (SCCI) is proposed built around a simple circuit utilizing a thyristor and a capacitor. It is designed to inject additional short circuit current in microgrids and weak grids. This allows the use of conventional miniature circuit breakers (MCB), even when the grid itself is not able to supply sufficient short circuit current.

The proposed SCCI was verified by introducing a short circuit in an experimental setup, where the faulty circuit was isolated by successfully tripping the MCB. This was achieved without violation immunity limits for IT-equipment. A PC connected to the same local grid as the short circuit, was able to operate without interruption.

Future work involves developing a more detailed MCB model to calculate the required capacitor value requirements more precisely.
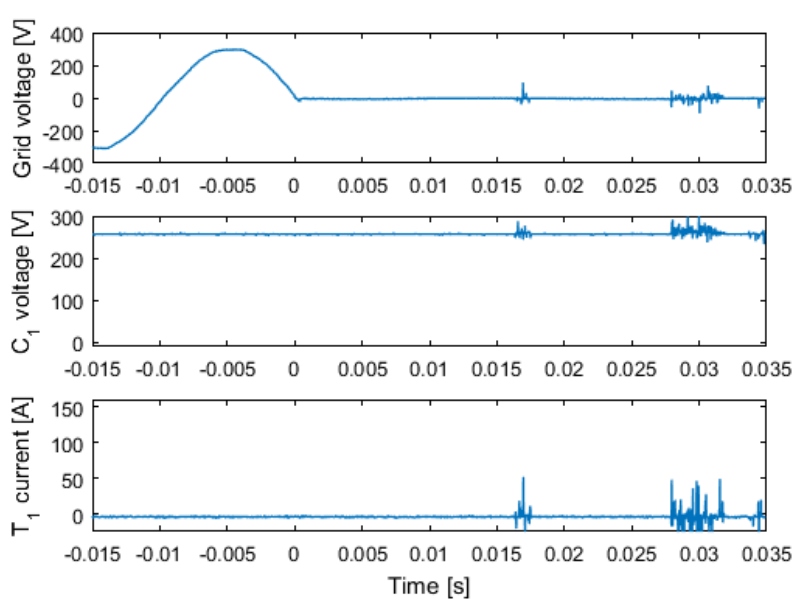

Fig. 10. Short circuit with SCCI deactivated

\section{ACKNOWLEDGMENT}

The authors would like to acknowledge the master student Qi Gao for his contributions to the topic in his master thesis.

\section{REFERENCES}

[1] IEC, "IEC 60898-1 Electrical accessories Circuit-breakers for overcurrent protection for household and similar installations - Part 1: Circuit-breakers for a.c. operation," ed. 1.2, 2003.

[2] IEEE, "1547.4 - IEEE Guide for Design, Operation, and Integration of Distributed Resource Island Systems with Electric Power Systems," 2011.

[3] W. Jiang, Z.-y. He, and Z.-q. Bo, "The Overview of Research on Microgrid Protection Development," in Intelligent System Design and Engineering Application (ISDEA), 2010 International Conference on, 2010, pp. 692-697.

[4] T. S. Ustun, C. Ozansoy, and A. Zayegh, "Modeling of a Centralized Microgrid Protection System and Distributed Energy Resources According to IEC 61850-7-420," IEEE Transactions on Power Systems, vol. 27, pp. 1560-1567, 2012.

[5] M. R. Islam and H. A. Gabbar, "Analysis of Microgrid protection strategies," in Smart Grid Engineering (SGE), 2012 IEEE International Conference on, 2012, pp. 1-6.

[6] T. S. Ustun, C. Ozansoy, and A. Zayegh, "A microgrid protection system with central protection unit and extensive communication," in Environment and Electrical Engineering (EEEIC), 2011 10th International Conference on, 2011, pp. 1-4.

[7] F. Van Overbeeke, "Fault current source to ensure the fault level in inverter-dominated networks," in Electricity Distribution - Part 1, 2009. CIRED 2009. 20th International Conference and Exhibition on, 2009, pp. $1-4$.

[8] IEC, "IEC 60941-2 Low-voltage switchgear and controlgear - Part 2: Circuit-breakers," ed. 4.2, 2013.

[9] ABB, "Miniature Circuit Breaker S 200/S 200 M datasheet," 2012.

[10] IEC, "NEK IEC 61000-4-11 Electromagnetic compatibility (EMC) Part 4-11: Testing and measurement techniques - Voltage dips, short interruptions and voltage variations immunity tests," ed, 2004.

[11] IEC, "NEK IEC 61000-4-34 Electromagnetic compatibility (EMC) Part 4-34: Testing and measurement techniques - Voltage dips, short interruptions and voltage variations immunity tests for equipment with mains current more than 16 A per phase," ed, 2009.

[12] R. Teodorescu, M. Liserre, and P. Rodríguez, Grid Converters for Photovoltaic and Wind Power Systems: Wiley, 2011. 